\title{
THE STATUS OF SOUTHERN WHITE-CHEEKED GIBBON (Nomascus siki) IN TRUONG SON KEY BIODIVERSITY AREA
}

\author{
Nguyen Dinh Duy, ${ }^{1, *}$ Dang Ngoc Can', Le Trong Trai ${ }^{3}$, Le Van $\mathrm{Ninh}^{3}$, \\ Tran Dang Hieu ${ }^{3}$, Ha Van $\mathrm{Nghia}^{3}$, Trinh Thi Mai ${ }^{3}$, Ly Ngoc Tu ${ }^{1,4}$ \\ ${ }^{1}$ Institute of Ecology and Biological Resources, VAST, Vietnam \\ ${ }^{2}$ Center for Biodiversity and Biosafety \\ ${ }^{3}$ Viet Nature Conservation Centre \\ ${ }^{4}$ Center of Science and Technology, Hanoi Metropolitan University \\ Received 3 December 2019, accepted 5 March 2020
}

\begin{abstract}
The Southern white-cheeked crested gibbon, Nomascus siki, is an endemic primate to Vietnam and Laos, and has been identified as a nationally and globally endangered species (EN). However, little information is known on the status of the species in Vietnam generally and in the Truong Son key biodiversity area (Truong Son KBA) particularly. In order to explore the current status of the species in the Truong Son KBA, we conducted field surveys in 2018 and 2019. Analysis of the survey data shows 149 groups of gibbon in the 4 study areas. Combined with results of similar-techniqued survey in 2016 on the same species in Khe Nuoc Trong forest, we identified at least 252 gibbon groups and estimated 425 gibbon groups in the entire Truong Son KBA. These gibbon groups are mainly distributed in medium-rich evergreen closed forests in mountainous areas of the west Truong Son KBA, adjacent to the Vietnam-Laos border.
\end{abstract}

Keywords: Biodiversity area, southern white-cheeked gibbon, distribution, Truong Son range, Laos, Vietnam.

Citation: Nguyen Dinh Duy, Dang Ngoc Can, Le Trong Trai, Le Van Ninh, Tran Dang Hieu, Ha Van Nghia, Trinh Thi Mai, Ly Ngoc Tu, 2020. The status of southern white-cheeked gibbon (Nomascus siki) in Truong Son key biodiversity area. Tap chi Sinh hoc, 42(1): 61-72. https://doi.org/10.15625/0866-7160/v42n1.14762.

*Corresponding author email: nguyenduyfuv@gmail.com

(C2020 Vietnam Academy of Science and Technology (VAST) 


\title{
HIỆN TRẠNG CỦA VƯợN ĐEN MÁ TRẮNG SIKI (Nomascus siki) TẠI VÙNG ĐA DẠNG SINH HỌC TRỌNG ĐIỂM TRƯỜNG SƠN
}

\author{
Nguyễn Đình Duy1,*, Đặng Ngọc Cần², Lê Trọng Trải ${ }^{3}$, Lê Văn Ninh ${ }^{3}$, \\ Trần Đặng Hiếu ${ }^{3}$, Hà Văn Nghĩa ${ }^{3}$, Trịnh Thị Mai ${ }^{3}$, Lý Ngọc Tú ${ }^{1,4}$ \\ ${ }^{1}$ Viện Sinh thái và Tài nguyên sinh vật, Viện Hàn lâm Khoa học và Công nghệ Việt Nam \\ ${ }^{2}$ Trung tâm Đa dạng và An toàn sinh học \\ ${ }^{3}$ Trung tâm Bảo tồn Thiên Nhiên Việt \\ ${ }^{4}$ Trung tâm Khoa học và Công nghệ, Trường Đại học Thủ đô Hà Nội
}

Ngày nhận bài 3-12-2019, ngày chấp nhận 5-3-2020

\section{TÓM TÁT}

Vượn đen má trắng siki Nomascus siki là loài linh trưởng đặc hữu của Việt Nam và Lào, được xác định là loài Nguy cấp (EN) ở phạm vi quốc gia và toàn cầu. Tuy nhiên, còn ít thông tin về tình trạng của loài này ở Việt Nam nói chung và ở vùng đa dạng sinh học trọng điểm Trường Sơn (Truong Son KBA) nói riêng. Để tìm hiểu về hiện trạng của loài tại vùng đa dạng sinh học trọng điểm Trường Sơn, chúng tôi đã tiến hành các đợt điều tra thực địa trong 2 năm 2018 và 2019 . Phân tích các kết quả điều tra đã ghi nhận 149 đàn vượn trong 4 khu vực. Kết hợp với kết quả điều tra năm 2016, chúng tôi xác định có ít nhất 252 đàn và ước tính có khoảng 425 đàn vượn trong toàn bộ vùng đa dạng sinh học trọng điểm Trường Sơn. Các đàn vượn này chủ yếu phân bố tại các khu vực rừng kín thường xanh trung bình-giàu trên núi đất ở khu vực phía Tây của vùng đa dạng sinh học trọng điểm Trường Sơn, tiếp giáp với biên giới Việt Nam-Lào.

Từ khóa: Đa dạng sinh học, vượn đen má trắng siki, phân bố, rừng thường xanh, Trường Sơn.

*Dịa chỉ liên hệ email: nguyenduyfuv@gmail.com

\section{MỞ ĐẦU}

Vượn đen má trắng siki Nomascus siki (Delacour, 1951) là một trong sáu loài vượn hiện được ghi nhận phân bố tại Việt Nam hiện nay. Loài này trước kia được cho là phân loài của Vượn đen má trắng Nomascus leucogenys (Ogilby, 1840) (Geissmann 1993, 1994, 1995; Geissmann et al., 2000), sau đó được tách ra thành loài độc lập (Groves, 2001; Mootnick, 2006; Geissmann, 2007; Van Ngoc Thinh et al., 2010b; Van Ngoc Thinh et al., 2010c; Van Ngoc Thinh et al., 2010e; Mootnick \& Fan Pengfei, 2011; Roos et al., 2013). Đây là loài linh trưởng đặc hữu của Việt Nam và Lào, chỉ phân bố trong một khu vực rất nhỏ ở miền Trung Việt Nam và miền Nam Lào (Rawson et al., 2011). Sự thiếu những thông tin làm cho tình trạng của loài này không rõ ràng nhất trong các loài vượn ở Việt Nam (Rawson et al., 2011). Hiện nay, ở phạm vi toàn cầu, $N$. siki được phân hạng ở mức Nguy cấp (EN) trong Danh lục Đỏ của Hiệp hội Bảo tồn thiên nhiên quốc tế (IUCN, 2019) và thuộc Phụ lục I của Công ước về buôn bán quốc tế các loài động vật, thực vật hoang dã nguy cấp (CITES, 2019).

Các nghiên cứu đến nay đều khẳng định ở Việt Nam, N. siki phân bố ở 3 tỉnh Hà Tĩnh, Quảng Bình và Quảng Trị, trong đó chủ yếu ở tỉnh Quảng Bình. Chưa rõ giới hạn phân bố về phía Bắc của $N$. siki, có thể nằm ở gần khu Bảo tồn thiên nhiên (KBTTN) Kẻ Gô̂, tỉnh Hà Tĩnh và KBTTN Khe Nét, tỉnh Quảng Bình (Rawson et al., 2011); một số 
tác giả khác cho rằng $N$. siki bị giới hạn bởi sông Rào Nây, phía Bắc KBTTN đề xuất Khe Ve tỉnh Quảng Bình (Van Ngoc Thinh et al., 2010 a, d; Roos et al., 2013); về phía Nam đến sông Thạch Hãn, tỉnh Quảng Trị (Van Ngoc Thinh et al., 2010a; Rawson et al., 2011; Roos et al., 2013). Trong phạm vi quốc gia, loài này được phân hạng ở mức Nguy cấp (EN) trong Sách đỏ Việt Nam năm 2007 và thuộc nhóm IB trong Nghị định 06/2019/NĐ-CP của Chính phủ nước Cộng hòa xã hội chủ nghĩa Việt Nam.

Việc lập kế hoạch và các giải pháp bảo tồn để bảo vệ một loài đòi hỏi sự hiểu biết về phân bố và tình trạng quần thể của loài trong tự nhiên (Cowlishaw \& Dunbar, 2000). Đến nay, thông tin về số lượng và phân bố chủ yếu được ghi nhận qua phỏng vân hoặc qua các đợt điều tra chung về đa dạng sinh học cách đây từ 10 đến 15 năm (Le Manh Hung et al., 2002; Le Trong Dat et al., 2006; Haus et al., 2009; Nguyen Xuan Dang et al., 2012). Do đó, việc điều tra thu thập thông tin về tình trạng quần thể và phân bô của $N$. siki làm cơ sở cho công tác quản lý, bảo tồn loài vượn quý hiếm này rất cân thiêt.

Vùng đa dạng sinh học trọng điểm Trường Sơn (Truong Son KBA) được xác định thuộc vùng phân bố phía Nam của $N$. siki tại Việt Nam. Khu vực này nằm ở phía Tây Nam tỉnh Quảng Bình và phía Bắc tỉnh Quảng Trị bao gồm diện tích quản lý của 5 đơn vị: lâm trường Trường Sơn, rừng phòng hộ Long Đại, lâm trường Khe Giữa, KBTTN Khe Nước Trong và KBTTN Bắc Hướng Hóa. Những giá trị nổi bật về đa dạng sinh học của vùng đã được khẳng định (CEPF, 2012). Hiện nay, khu vực này đang bảo vệ một diện tích lớn rừng nhiệt đới thường xanh còn tính chất nguyên sinh, là sinh cảnh phù hợp cho vượn sinh sống và phát triển. Tuy nhiên, hầu như chưa có cuộc điều tra chuyên sâu nào về vượn được thực hiện. Năm 2016, một cuộc điều tra tại KBTTN Khe Nước Trong đã ghi nhận 103 đàn $N$. siki và ước tính có khoảng 146 đàn trên diện tích khoảng 104 km² (Đặng Ngọc Cần và nnk., 2017). Kết quả này cho thấy, KBTTN Khe Nước Trong tuy chỉ là một phần của Truong Son KBA nhưng là một trong số ít khu vực phân bố quan trọng nhất của loài $N$. siki được biết đến tại Việt Nam. Trong khi phần lớn diện tích rừng thuộc Truong Son KBA vẫn chưa được điều tra một cách bài bản. Do đó, chúng tôi thực hiện điều tra này nhằm xác định tình trạng quần thể của $N$. siki tại các khu vực phân bố phía Nam của loài thuộc Truong Son KBA ngoại trừ khu BTTN Khe Nước Trong đã điều tra năm 2016.

Mục tiêu của điều tra là xác định được hiện trạng quần thể và phân bố của loài $N$. siki trong vùng Truong Son KBA. Điều tra được thực hiện từ tháng 4/2018 đến tháng 3/2019 với tổng số 82 ngày thực địa.

\section{VÂT LIỆU VÀ PHƯƠNG PHÁP NGHIÊN CƯU}

\section{Khu vực nghiên cứu}

Truong Son KBA có tổng diện tích khoảng $1.221 \mathrm{~km}^{2}$ nằm ở phía Tây Nam tỉnh Quảng Bình và phía Bắc tỉnh Quảng Trị, miền Trung Việt Nam; giáp với biên giới Việt Nam - Lào. Địa hình bị chia cặt mạnh với các dãy núi chạy theo hướng Tây Bắc-Đông Nam điển hình của khu vực Bắc Trường Sơn, chủ yếu là hệ thống núi thấp có độ cao trung bình dưới $1000 \mathrm{~m}$. Diện tích núi đất chiếm khoảng 90\% tổng diện tích của khu vực, núi đá vôi điển hình chiếm khoảng $10 \%$ tập trung tại khu vực thuộc rừng phòng hộ Long Đại và một phần nhỏ thuộc KBTTN Bắc Hướng Hóa (Dang Ngoc Can et al., 2012). Một dải rừng thường xanh trên núi đất từ trung bình đến giàu kéo dài liên tục từ bắc đến nam, xen giữa là hệ thống núi đá vôi tạo thành sinh cảnh sống vô cùng thuận lợi cho vượn. Đây được xác định bao gồm toàn bộ các khu vực phân bố phía Nam của loài $N$. siki tại Việt Nam hiện nay.

Với mức độ đa dạng các loại sinh cảnh, sự liền mạch và khả năng kết nối cao với các khu vực khác, Truong Son KBA của Việt Nam cùng với Khu vực ĐDSH Laving-Laveun và khu vực ĐDSH Bắc Xe Bangfai của Lào được xác định là các khu vực bảo tồn đa dạng sinh học trọng điểm nằm trong hành lang bảo tồn đa dạng sinh học Vùng đất thấp Quảng BìnhQuảng Trị-Xe Bangfai có diện tích $3.819 \mathrm{~km}^{2}$. Khu vực này hiện là một trong 66 hành lang 
bảo tồn đa dạng sinh học trong điểm nóng đa dạng sinh học Indo-Burma (là một trong 25 điểm nóng về đa dạng sinh học toàn cầu). Theo Quỹ Hợp tác Hệ sinh thái quan trọng (CEPF, 2012) hành lang bảo tồn này hiện đang là ngôi nhà chung của ít nhất 3 loài động vật có ý nghĩa bảo tồn toàn cầu cần được bảo tồn khẩn cấp là vượn đen má trắng siki Nomascus siki; Sao la Pseudoryx nghetinhensis; Chà vá chân nâu Pygathrix nemaeus và nhiều loài động vật, thực vật có ý nghĩa bảo tồn cao khác.

\section{Lựa chọn khu vụ̣c khảo sát}

Trước khi tiến hành điều tra, chúng tôi phỏng vấn các cán bộ, nhân viên bảo vệ rừng và người dân địa phương để thu thập thông tin. Các thông tin phỏng vấn bao gồm việc xác định những khu vực phân bố của $N$. siki, tình trang của loài, điều kiện rừng khu vực phân bố và áp lực săn bắt. Đồng thời các thông tin về khả năng tiếp cận, quãng đường di chuyển, các khu vực có thể đóng lán cũng được thu thập. Mục tiêu của các cuộc phỏng vấn để nắm được các thông tin sơ bộ, trên cơ sở đó thiết kế chi tiết các điểm nghe và lập kế hoạch thực địa.

Theo thông tin phỏng vấn, vượn được ghi nhận tại nhiều điểm thuộc Truong Son KBA, trong đó tập trung tại các khu vực phía Tây của vùng. Những khu vực này cung cấp môi trường sống tốt cho vượn do ít bị xáo trộn bởi hoạt động của con người hơn so với phần phía Đông của Truong Son KBA. Người dân địa phương cho biết không có thông tin nào về vượn ở các khu vực phía Đông. Do đó, chúng tôi quyết định tập trung khảo sát vào phần phía Tây của vùng Truong Son KBA dọc theo biên giới Việt Nam - Lào.

\section{Phương pháp nghiên cứu}

Các loài vượn mào thường sống trên tán cây và rất nhạy cảm với sự hiện diện của con người. Vì thế việc quan sát vượn trong thực địa rât khó khăn, đặc biệt trong các đợt điều tra ngắn (Geissmann, 1993). Tuy nhiên, vượn thường phát ra các tiếng hót to, dài, lặp lại, đặc trưng cho loài (Geissmann, 1993; Geissmannet et al., 2000). Vì vậy, phương pháp điều tra tiếng hót theo điểm nghe (Brockelman \& Ali,
1987) được sử dụng để thu thập số liệu tại khu vực nghiên cứu (Brockelman et al., 1987; Brockelman et al., 1993; Geissmann, 1993; Geissmann et al., 2000).

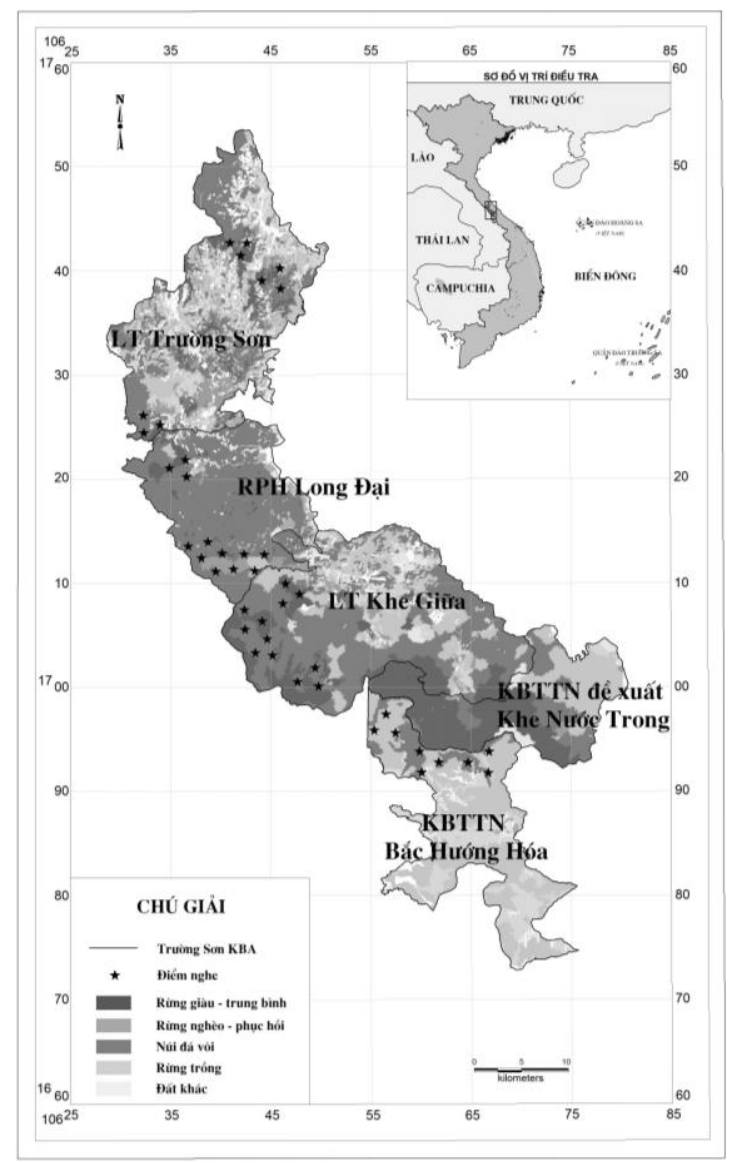

Hình 1. Vị trí các điểm nghe

Với tổng số 42 điểm nghe tiếng vượn được thiết lập (hình 1) trong đó 3 điểm nghe thực hiện điều tra đồng thời (hình 2). Mỗi điểm nghe có 2-3 thành viên thu thập số liệu từ 5:00-9:00 sáng trong 3 ngày liên tục. Qua các điều tra tại KBTTN Khe Nước Trong, nơi có địa hình tương tự, chúng tôi xác định khoảng cách nghe được tiếng vượn hót tối đa tại khu vực là $1,5 \mathrm{~km}$ (Đặng Ngọc Cần và nnk., 2017) do đó, các điểm nghe được bố trí cách xa nhau khoảng $1,5-2 \mathrm{~km}$ tùy thuộc vào địa hình. Tổng diện tích điều tra được xác định là $223,133 \mathrm{~km}^{2}$. Các điểm nghe được bố trí trên đỉnh hoặc dông núi (nếu đỉnh núi quá cao không thể tiếp cận được trước 5:00 giờ 
sáng). Các điểm nghe được thiết kế phân bố khá đều nhau nhằm tăng khả năng ghi nhận các đàn vượn trong khu vực khảo sát.

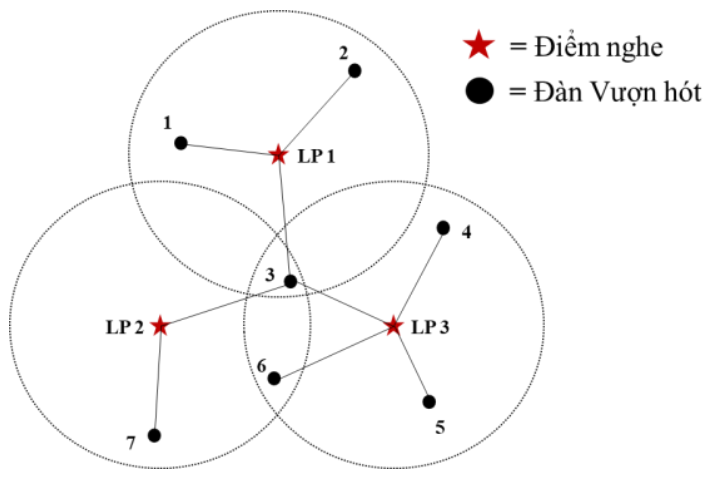

Hình 2. Mô tả 3 điểm nghe điều tra đồng thời

Trong quá trình điều tra, người điều tra sử dụng la bàn để xác định hướng của các đợt khi nghe được tiếng vượn hót, ước lượng khoảng cách tới các đàn vượn thông qua độ lớn của âm thanh và bản đồ địa hình, xác định thời gian bắt đầu và kết thúc của tất cả các đợt hót, đặc điểm tiếng hót, đồng thời ghi âm các đợt hót bằng máy ghi âm chuyên dụng. Điều kiện thời tiết cũng được ghi lại của mỗi ngày điều tra. Cuối cùng, sự hiện diện của các động vật hoang dã khác trong khu vực được ghi lại, cũng như bất kỳ quan sát trực tiếp nào về vượn.

\section{Phân tích số liệu}

Vị trí các đàn vượn hót được xác định căn cứ vào các dữ liệu như góc phương vị, ước lượng khoảng cách đàn vượn hót đển vị trí điểm nghe dựa trên âm lượng và các dữ liệu về sinh cảnh, địa hình của khu vực. Vị trí của các đàn vượn được đánh dấu trên bản đồ hiện trạng rừng và bản đồ địa hình. Việc phân biệt các đàn vượn còn được thực hiện qua việc so sánh vị trí của từng đàn. Nếu vị trí các đàn vượn hót được phát hiện nằm cách nhau trên $500 \mathrm{~m}$ thì được coi là đàn riêng biệt vì vượn có tập tính sống theo lãnh thồ, diện tích vùng sống vào khoảng 40 ha (Brockelman \& Ali, 1987).

Số liệu điều tra được thống kê và xử lý bằng phần mềm Excel 2013, diện tích nghe chồng lấn của các điểm nghe và bản đồ khu vực phân bố được xây dựng bằng phần mềm Mapinfo 11.5. Trên cơ sở số lượng đàn vượn ghi nhận được trong quá trình điều tra, sử dụng phương pháp của Jiang et al. (2006) để tính xác suất hót trong 1 ngày. Theo Vũ Tiến Thịnh và Đồng Thanh Hải (2015) để ước tính kích thước quần thể trong toàn bộ diện tích sinh cảnh phù hợp của khu vực thông qua sử dụng hệ số hiệu chỉnh có trọng số (WC).

Trong các cuộc điều tra vượn rất khó để tránh chồng lấn diện tích của các điểm nghe. Khi các điểm nghe gần nhau được khảo sát, các khu vực chồng lấn được khảo sát trong nhiều ngày hơn các khu vực không chồng lấn. Vì thế, việc dự đoán sử dụng một số hiệu chỉnh chung có vẻ không phù hợp. Kết quả ước tính sô lượng đàn vượn có thể cao hơn thực tế. Và đặc biệt quan trọng nếu khu vực chồng lấn có diện tích lớn hơn các khu vực không chồng lấn. Vì vậy, việc sử dụng một hệ số hiệu chỉnh có trọng số là một điều cần thiết. Ngoài ra, hệ số hiệu chỉnh có trọng số cũng cho phép sự linh hoạt trong thiết kế điều tra, các nổ lực khác nhau có thể được áp dụng cho các điểm nghe khác nhau.

Hệ số hiệu chỉnh có trọng số được tính theo công thức:

$$
\mathrm{WC}=\frac{1}{\mathrm{~A}} \sum_{\mathrm{i}=1}^{\mathrm{m}} \mathrm{aiCi}
$$

Trong đó: WC: Hệ số hiệu chỉnh có trọng số; $\mathrm{a}_{\mathrm{i}}$ : Diện tích điều tra trong i ngày; $\mathrm{C}_{\mathrm{i}}$ : Hệ số hiệu chỉnh áp dụng cho khu vực điều tra trong i ngày, với $\mathrm{Ci}=1-(1-\mathrm{pi})^{\mathrm{i}}$; $\mathrm{A}$ : Tổng diện tích điều tra; m: Số ngày khảo sát tối đa một diện tích nghiên cứu.

Số ngày khảo sát tối đa một diện tích nghiên cứu được tính như sau:

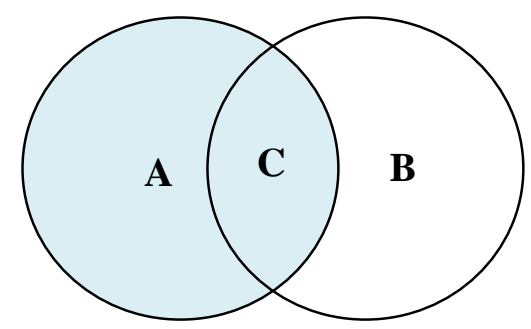

Hình 3. Giải thích về cách xác định "Hệ số hiệu chỉnh có trọng số” 
Khu A được khảo sát trong 1 ngày: Hệ số hiệu chỉnh $\mathrm{C}=1-(1-\mathrm{p} 1)^{1}$;

Khu $\mathrm{B}$ được khảo sát trong 2 ngày: Hệ số hiệu chỉnh $\mathrm{C} 2=1-(1-\mathrm{p} 1)^{2}$;

Khi đó khu $\mathrm{C}$ sẽ được khảo sát trong 3 ngày: Hệ số hiệu chỉnh $\mathrm{C} 3=1-(1-\mathrm{p} 1)^{3}$;

Các yếu tố điều chỉnh luôn luôn $<1$.

Số lượng các đàn vượn trong diện tích khảo sát tại mỗi khu vực được ước tính bằng cách chia số lượng các đàn nghe được cho hệ số hiệu chỉnh có trọng số. Từ đó tồng số các đàn vượn ở mỗi khu vực được ngoại suy dựa trên số lượng ước tính các đàn vượn trong diện tích khảo sát tại mỗi khu vực và kích thước môi trường sống.

Diện tích sinh cảnh phù hợp cho vượn được chúng tôi xác định bằng phương pháp mô hình hóa ổ sinh thái dựa trên phần mềm MaxEnt kết hợp với các kết quả phỏng vấn và điều tra thực địa. Chúng tôi sử dụng các vị trí ghi nhận của đàn vượn trong quá trình điều tra thực địa là các dữ liệu về sự có mặt cho mô hình MaxEnt. Vi trí các đàn vượn được xác định bao gồm cả các vị trí bắt gặp và các vị trî được xác định từ tiếng hót của chúng. Vị trî của các đàn vượn được ghi nhận trong đợt điều tra này được sử dụng cho dữ liệu đầu vào của mô hình. Mô hình được xây dựng nhằm xác định sự thích hợp về sinh cảnh sông của các đàn vượn. Vì vậy, các biến liên quan trực tiếp đến chất lượng sinh cảnh sống của chúng được sử dụng. Vượn thường sinh sống ở trên các tầng tán cây cao, nơi các khu rừng nguyên sinh, ít bị tác động (Geissmann et al., 2000). Do đó, các biến được sử dụng bao gồm các loại trạng thái rừng theo bản đồ kiểm kê rừng năm 2016 của tỉnh Quảng Bình và tỉnh Quảng Trị, đã được chúng tôi xác định và cập nhật của bản đồ tại các khu vực có đàn vượn phân bố. Ngoài ra, chúng tôi sử dụng ba biến khác liên quan đến trang thái rừng là: rừng tự nhiên, độ che phủ của tầng tán cây và chiều cao tầng tán cây của rừng (GLAD-UMD and SERVIRMekong, 2017) để xác định diện tích sinh cảnh phù hợp cho vượn.

\section{KẾT QUẢ}

\section{Hiện trạng quần thể}

Trên cơ sở phân tích 393 đợt hót từ 42 điểm nghe trong tổng diện tích điều tra $223,133 \mathrm{~km}^{2}$ thuộc Truong Son KBA, chúng tôi đã xác định có ít nhất 149 đàn $N$. siki. Các khu vực thuộc rùng phòng hộ Long Đại và KBTTN Bắc Hướng Hóa ghi nhận được nhiều nhất với lần lượt là 52 và 45 đàn, lâm trường Khe Giữa ghi nhận được 38 đàn, lâm trường Trường Sơn chỉ ghi nhận được 14 đàn. Số lượng các đàn vượn ghi nhận được thể hiện trong bảng 1 .

Bảng 1. Số lượng đàn vượn được ghi nhận

\begin{tabular}{|c|c|c|}
\hline $\begin{array}{c}\text { Đơn vị quản lý } \\
\text { (Diện tích điều tra }\left(\mathrm{km}^{2}\right) \text { ) }\end{array}$ & Tên khu vực điều tra & Số lượng đàn vượn ghi nhận \\
\hline \multirow{3}{*}{$\begin{array}{l}\text { LT Trường Sơn } \\
(50,543)\end{array}$} & Đá Vách & 0 \\
\hline & U Bò & 6 \\
\hline & Bản Mây & 8 \\
\hline \multirow{4}{*}{$\begin{array}{l}\text { RPH Long Đại } \\
(58,148)\end{array}$} & Đìu Đo & 13 \\
\hline & Lồ Ô 1 & 14 \\
\hline & Lồ Ô 2 & 11 \\
\hline & Lồ Ô 3 & 14 \\
\hline \multirow{4}{*}{$\begin{array}{l}\text { LT Khe Giữa } \\
\quad(68,274)\end{array}$} & Chút Mút 1 & 12 \\
\hline & Chút Mút 2 & 8 \\
\hline & Chút Mút 3 & 8 \\
\hline & Chút Mút 4 & 10 \\
\hline \multirow{3}{*}{$\begin{array}{c}\text { KBTTN Bắc Hướng Hóa } \\
(46,168)\end{array}$} & Cuôi & 14 \\
\hline & Cợp & 18 \\
\hline & Chà Lỳ & 13 \\
\hline Tổng số & & 149 \\
\hline
\end{tabular}




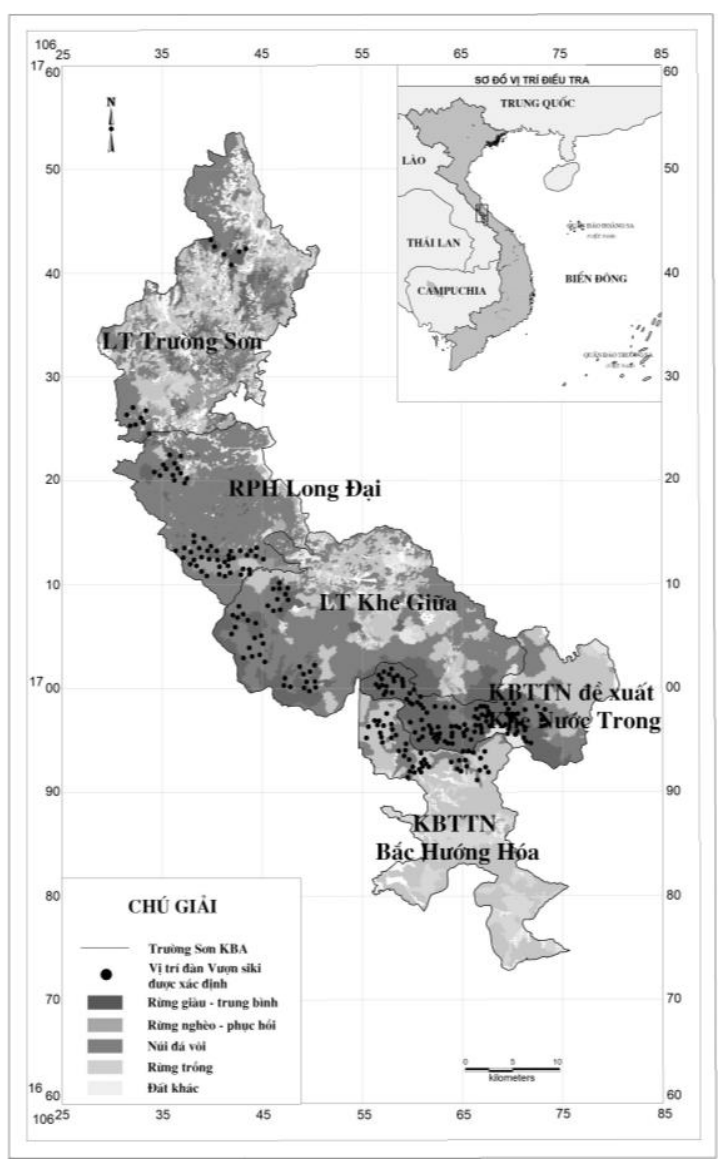

Hình 4. Vị trí các đàn Vượn được xác định

Cùng với kết quả điều tra tại KBTTN Khe Nước Trong năm 2016 (Đặng Ngọc Cần và nnk., 2017) đã ghi nhận 103 đàn, chúng tôi xác định có 252 đàn $N$. siki trong vùng Truong Son KBA. Vị trí các đàn $N$. siki được thể hiện trong hình 3.

Diện tích rừng các khu vực điều tra được quản lý bởi nhiều đơn vị khác nhau, với mục tiêu quản lý và bảo vệ khác nhau, do đó có sự khác biệt về chất lượng sinh cảnh cũng như mức độ bị tác động. Điều này đã tạo ra sự không tương đồng về sinh cảnh sống của vượn cũng như mật độ và khả năng phân bố của chúng. Vì vậy, chúng tôi tiến hành xác định diện tích sinh cảnh phù hợp và ước tính số lượng đàn vượn riêng cho từng khu vực.

\section{Diện tích sinh cảnh phù họ̣p}

Đối với nhu cầu về môi trường sống của $N$. siki, các cuộc khảo sát của chúng tôi cho thấy, loài này thường được ghi nhận trong những khu vực rừng kín thường xanh trên núi đất và các khu vực liền kề thuộc rừng kín thường xanh trên núi đá vôi. $N$. siki cũng cho thấy mối quan hệ chặt chẽ với các khu vực có chất lượng rừng tốt với chiều cao tán rừng lớn và khép tán. Các kết quả điều tra cho thấy các nhóm $N$. siki không được phát hiện sâu bên trong các khu vực núi đá vôi rộng lớn. Nhưng chúng thường được ghi nhận ở rìa các khu vực núi đá vôi và các thung lũng chạy giữa các khối núi đá vôi. $N$. siki cũng được ghi nhận tại một số khu vực rừng bị tác động mạnh do khai thác gỗ nhưng đã có thời gian phục hồi.

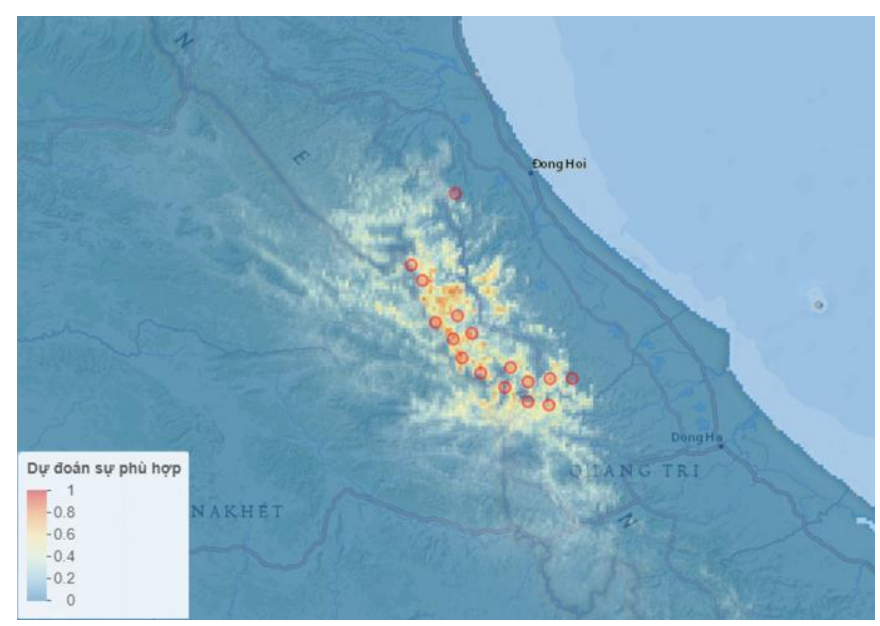

Hình 5. Kết quả chạy mô hình ổ sinh thái dựa trên phần mềm MaxEnt

(Điểm chấm đỏ là vị trí đàn Vượn được sử dụng để chạy mô hình) 
Kết quả chạy mô hình xác định mức độ thích hợp của sinh cảnh rừng đối với loài $N$. siki cho toàn bộ tỉnh Quảng Bình và Quảng Trị thông qua sử dụng bản đồ hiện trạng rừng đã được cập nhật trong quá trình điều tra kêt hợp với 3 biến môi trường: Rừng tự nhiên, độ che phủ của tầng tán và chiều cao cây rừng (GLAD-UMD and SERVIRMekong, 2017) đã chỉ ra phần lớn $(73,00 \%)$ diện tích của Truong Son KBA là sinh cảnh phù hợp với loài $N$. siki (hình 5). Tuy nhiên, qua các kết quả phỏng vấn cán bộ quản lý và người dân địa phương, chúng tôi nhận thấy chỉ có khoảng 41,83\% diện tích có sự tồn tại của loài $N$. siki, và khoảng 5,00\% diện tích thuộc các khu vực liền kề thuộc rừng kín thường xanh trên núi đá vôi, các thung lũng trong khu vực núi đá vôi đôi khi có $N$. siki (không thường xuyên và hiếm gặp). Tổng diện tích sinh cảnh phù hợp cho toàn vùng Truong Son $\mathrm{KBA}$ được xác định khoảng $510,808 \mathrm{~km}^{2}$ trong đó bao gồm $406,810 \mathrm{~km}^{2}$ tại $4 \mathrm{khu}$ vực điều tra đợt này và $103,998 \mathrm{~km}^{2}$ tại KBTTN Khe Nước Trong (Đặng Ngọc Cần và nnk, 2017), diện tích sinh cảnh phù hợp của mỗi khu vực được thống kê trong bảng 2 .

Bảng 2. Diện tích sinh cảnh phù hợp

\begin{tabular}{|l|c|c|c|}
\hline \multicolumn{1}{|c|}{ Đơn vị quản lý } & $\begin{array}{c}\text { Tồng diện } \\
\text { tích }\left(\mathrm{km}^{2}\right)\end{array}$ & $\begin{array}{c}\text { Diện tích sinh cảnh } \\
\text { phù hợp }\left(\mathrm{km}^{2}\right)\end{array}$ & $\begin{array}{c}\text { Diện tích sinh cảnh phù } \\
\text { hợp/tổng diện tích }(\%)\end{array}$ \\
\hline LT Trường Sơn & 288,84 & 81,37 & 28,17 \\
\hline RPH Long Đại & 265,03 & 87,56 & 33,03 \\
\hline LT Khe Giữa & 356,69 & 173,54 & 48,65 \\
\hline KBTTN Bắc Hướng Hóa & 206,46 & 64,34 & 31,16 \\
\hline Tồng & 1117,02 & 406,81 & 36,42 \\
\hline
\end{tabular}

\section{Ước tính kích thước quần thể}

Dựa trên số lượng đàn vượn ghi nhận được tại các điểm nghe, chúng tôi đã tính xác suất hót trong một ngày $\mathrm{p}(1)$ của $N$. siki theo phương pháp của Jiang et al. (2006). Từ đó xác định hệ số hiệu chỉnh có trọng số (WC) theo Vũ Tiến Thịnh và Đồng Thanh Hải (2015) cho mỗi khu vực. Kết quả được trình bày trong bảng 3 .

Bảng 3. Xác định hệ số hiệu chỉnh

\begin{tabular}{|l|l|l|}
\hline \multicolumn{1}{|c|}{ Đơn vị quản lý } & $\mathrm{p}(1)$ & $\mathrm{WC}$ \\
\hline Lâm trường Trường Sơn & 0,634 & 0,96 \\
\hline Rừng phòng hộ Long Đại & 0,609 & 0,96 \\
\hline Lâm trường Khe Giữa & 0,689 & 0,98 \\
\hline KBTTN Bằc Hướng Hóa & 0,439 & 0,85 \\
\hline
\end{tabular}

Qua các nỗ lực điều tra, với hệ số điều chỉnh có trọng số và tổng diện tích sinh cảnh phù hợp được xác định, chúng tôi ước tính kích thước quần thể $N$. siki cho các vùng khảo sát tại khu vực Truong Son KBA hiện ít nhất có khoảng 279 đàn $N$. siki, số đàn ước tính cho mỗi khu vực được thống kê trong bảng 4 .

Bảng 4. Ước tính kích thước quần thể

\begin{tabular}{|l|c|c|c|c|}
\hline \multicolumn{1}{|c|}{ Đơn vị quản lý } & $\begin{array}{c}\text { Diện tích điều } \\
\text { tra }\left(\mathrm{km}^{2}\right)\end{array}$ & $\begin{array}{c}\text { Số đàn } \\
\text { ghi nhận }\end{array}$ & $\begin{array}{c}\text { Diện tích sinh cảnh phù } \\
\text { hợp }\left(\mathrm{km}^{2}\right)\end{array}$ & $\begin{array}{c}\text { Số đàn ước } \\
\text { tính }\end{array}$ \\
\hline Lâm trường Trường Sơn & 50,543 & 14 & 81,37 & 24 \\
\hline Rừng phòng hộ Long Đại & 58,148 & 52 & 87,56 & 82 \\
\hline Lâm trường Khe Giữa & 68,274 & 38 & 173,54 & 99 \\
\hline KBTTN Bắc Hướng Hoá & 46,168 & 45 & 64,34 & 74 \\
\hline Tổng & 223,133 & 149 & 406,81 & 279 \\
\hline
\end{tabular}


The status of southern white-cheeked gibbon

Bảng 5. Số lượng đàn $N$. siki tại các khu vực trong toàn vùng phân bố

\begin{tabular}{|l|c|c|c|l|}
\hline \multicolumn{1}{|c|}{ Khu vực } & Tỉnh & $\begin{array}{c}\text { Diện tích } \\
\text { rừng }\left(\mathrm{km}^{2}\right)\end{array}$ & $\begin{array}{c}\text { Số } \\
\text { đàn }\end{array}$ & \multicolumn{1}{|c|}{ Nguồn } \\
\hline KBTTN Kẻ Gỗ/Khe Nét & $\begin{array}{c}\text { Hà Tĩnh/ } \\
\text { Quang Bình }\end{array}$ & 440,000 & 4 & Van Ngoc Thinh et al., 2010a \\
\hline $\begin{array}{l}\text { KBTTN đề xuất Giăng } \\
\text { Màn }\end{array}$ & $\begin{array}{c}\text { Hà Tĩnh/ } \\
\text { Quang Bình }\end{array}$ & 60,000 & 5 & $\begin{array}{l}\text { Le Khac Quyet, 2004; } \\
\text { Nguyen Manh Ha, 2005 }\end{array}$ \\
\hline KBTTN đề xuất Khe Ve & Quảng Bình & 100,000 & 7 & Nguyen Manh Ha, 2005 \\
\hline $\begin{array}{l}\text { VQG Phong Nha - Kẻ } \\
\text { Bàng }\end{array}$ & Quảng Bình & 857,540 & 50 & $\begin{array}{l}\text { Ruppell, 2007; Le Trong Dat } \\
\text { et al., 2009 }\end{array}$ \\
\hline Lâm trường Trường Sơn & Quảng Bình & 375,600 & 24 & Điều tra này \\
\hline Rừng phòng hộ Long Đại & Quảng Bình & 230,300 & 82 & Điều tra này \\
\hline Lâm trường Khe Giữa & Quảng Bình & 423,500 & 99 & Điều tra này \\
\hline KBTTN Khe Nước Trong & Quảng Bình & 103,998 & 146 & Đặng Ngọc Cần và nnk., 2017 \\
\hline KBTTN Bắc Hướng Hoá & Quảng Trị & 251,30 & 74 & Điều tra này \\
\hline
\end{tabular}

Cùng với kết quả điều tra tại KBTTN Khe Nước Trong năm 2016 (Đặng Ngọc Cần và nnk., 2017) đã ghi nhận 103 đàn và ước tính trong toàn bộ diện tích sinh cảnh phù hợp ở khu vực này có khoảng 146 đàn $N$. siki. Như vậy, chúng tôi xác định có 252 đàn và ước tính có 425 đàn $N$. siki trong vùng Truong Son KBA.

Thống kê các ghi nhận $N$. siki cho toàn vùng phân bố được tổng hợp trong bảng 5 .

\section{THẢO LUẬN}

Kết quả điều tra của chúng tôi đã cho thấy, vùng Truong Son KBA đang bao gồm các khu vực có quần thể $N$. siki lớn nhất đến nay được ghi nhận. Tuy nhiên, hiện nay chỉ có KBTTN Khe Nước Trong và KBTTN Bắc Hướng Hóa thuộc diện tích rừng được bảo vệ, các khu vực còn lại đang được quản lý bởi các công ty lâm nghiệp và ban quản lý rừng phòng hộ. Hay nói cách khác khoảng 41,3\% các đàn $N$. siki trong Truong Son $\mathrm{KBA}$ đang nằm ngoài các khu vực được bảo vệ mà ở đó săn bẳn và mất sinh cảnh sống cao hơn nhiều so với các khu rừng được bảo vệ. Thực tế cho thấy việc khai thác từng tác động thấp tại lâm trường Trường Sơn (theo chứng chỉ FSC) vẫn ảnh hưởng tiêu cực đến sinh cảnh sống và phân bố của loài $N$. siki. Tại đây chỉ ghi nhận 14 đàn vượn, trong khi đó khu liền kề là rừng phòng hộ Long Đại có 52 đàn vượn đã được ghi nhận.
Hiện nay, mặc dù rừng tự nhiên không được khai thác nhưng việc khai thác gỗ bất hợp pháp và xâm chiếm đất rừng tự nhiên vẫn đang xảy ra, điều này đã ảnh hưởng đến chất lượng rừng và diện tích phân bố của loài $N$. siki. Cùng với đó, các ghi nhận về săn bắt và buôn bán động vật hoang dã trong vùng cho thấy $N$. siki tuy không phải là đối tượng săn bắt của người dân địa phương nhưng vẫn còn ghi nhận vượn bị săn bắt. Đây thật sự là một thách thức đối với công tác bảo tồn loài $N$. siki ở Việt Nam.

Các kết quả điều tra trong thời gian qua chủ yếu được thực hiện tại các khu vực phân bố phía Nam của $N$. siki ở Việt Nam. Để có được thông tin cụ thể về hiện trạng của loài, tạo cơ sở cho công tác bảo tồn được hiệu quả, cần tiếp tục điều tra tình trạng tại các khu vực phân bố phía Bắc của loài như KBTTN Kẻ Gỗ/Khe Nét, KBTTN Giang Màn, KBTTN đề xuất Khe Ve, VQG Phong Nha-Kẻ Bàng.

Cùng với đó, các kết quả điều tra cho thấy các khu vực phân bố phía Nam của $N$. siki ở Việt Nam hiện đang bảo vệ số lượng lớn đàn hiện biết. Công tác bảo tồn loài $N$. siki nên tập trung tại các khu vực này.

\section{KẾT LUẬ̣N}

Hiện có 252 đàn và ước tính có khoảng 425 đàn $N$. siki tại 5 khu vực thuộc vùng Truong Son KBA. Trong đó các khu vực ghi nhận số đàn $N$. siki nhiều nhất là KBTTN Khe 
Nước Trong, lâm trường Khe Giữa và rừng phòng hộ Long Đại.

$N$. siki chủ yếu phân bố tại các khu vực rừng kín thường xanh trung bình-giàu trên núi đất của vùng Truong Son KBA.

\section{TÀI LIỆU THAM KHẢO}

Brockelman W.Y., Ali R., 1987. Methods of surveying and sampling forest primate populations; pp 23-62. In: Marsh CW \& Mittermeier RA (eds): Primate Conservation in the Tropical Rainforest. Alan R. Liss Inc., New York.

Brockelman W.Y., Srikosamatara S., 1993. Estimating density of gibbon groups by use of the loud songs. Am. J. Primatol. 29, 93-108.

CITES, 2019. Convention on International Trade in Endangered Species of Wild Fauna and Flora. Version 2019-11. <www.cites.org>. Downloaded on 30 November 2019.

Cowlishaw G., Dunbar R., 2000. Primate Conservation Biology. University of Chicago Press: Chicago. 498 pp. ISBN 0226-11637-9.

Critical Ecosystem Partnership Fund (CEPF), 2012. Indo-Burma Biodiversity Hotspot. Washington, DC, $381 \mathrm{pp}$

Dang Ngoc Can, Le Van Cham, Trinh Viet Cuong, Ngo Xuan Tuong, Le Manh Tuan, 2012. Report: The Biodiversity and Forest Ecosystem Services Assessment of Truong Son Important Bird Area, Quang Binh and Quang Tri provinces, Vietnam. BirdLife International Vietnam Programme.

Dang Ngoc Can, Nguyen Dinh Duy, Le Trong Trai, Le Van Ninh, Le Quoc Hieu, Tran Dang Hieu, 2017. Status survey of southern white-cheeked gibbon (Nomascus siki) in proposed Khe Nuoc Trong nature reserver, Le Thuy district, Quang Binh province. The 7-th National Conference on Ecology and Biological Resources, Ha Noi, 2017: 583-589.
Decree No. 06/ND-CP of the Prime Minister, 2019. Provisions on management and the List of endangered, precious and rare forest plants and animals from Vietnam's forests.

Geissmann T., 1993. Evolution of communication in gibbons (Hylobatidae). $\mathrm{PhD}$ thesis, Anthropological Institute, Zürich University, Switzerland.

Geissmann T., 1994. Systematik der Gibbons. Zeitschrift des Kölner Zoo 37: 65-77 (German text, English abstract).

Geiissmann T., 1995. Gibbon systematics and species identification. International Zoo News 42: 467-501.

Geissmann T., 2007. Status reassessment of the gibbons: results of the Asian primate red list workshop 2006. Gibbon Journal 3: 5-15.

Geissmann T., Nguyen Xuan Dang, Lormée N., Momberg F., 2000. Vietnam Primate Conservation Status Review 2000, Part 1: Gibbons. Fauna and Flora International Indochina Programme, Ha Noi.

Geissmann T., Orgeldinger M., 2000. The relationship between duet songs and pair bonds in siamangs, Hylobates syndactylus. Animal Behavior 60, 805-809.

GLAD-UMD and SERVIRMekong, 2017. National annual tree canopy structure and surface water dynamics products. Available at https://glad.umd.edu/sites/default/files/Vie tnam National_Data_Description.pdf, assessed on May/2019

Groves C. P., 2001. Primate Taxonomy, Smitsonian Institution Press, Washington and London, 350 pages.

Haus T., Vogt M., Forster B., Vu Ngoc Thanh, Ziegler T., 2009. Distribution and population densities of diurnal primates in the karst forests of Phong Nha-Ke Bang National Park, Quang Binh province, central Vietnam. International Journal of Primatology 30: 301-312. 
International Union for Conservation of Nature 2019. Nomascus siki. The IUCN Red List of Threatened Species. Version 2019-3.

Jiang X. L., Luo Z.H., Zhao S. Y., 2006. Status and distribution patterns of black crested gibbon (Nomascus concolor jingdongensis) in Wulian Mountains, Yunnan, China: Implications for conservation. Primates 47: 264-271.

Le Khac Quyet, 2004. A preliminary survey of primates in Nui Giang Man area, Quang Binh province, central Vietnam. Pages $45-51$ in T. Nadler, U. Streicher, and Ha Thang Long, editors. Conservation of Primates in Vietnam. Frankfurt Zoological Society, Ha Noi, Vietnam.

Le Manh Hung, Pham Duc Tien, Tordoff A. W., Nguyen Dinh Dung, 2002. Report: A rapid field survey of Le Thuy and Quang Ninh Districts, Quang Binh province, Vietnam. BirdLife International Vietnam Programme, Ha Noi, Vietnam.

Le Trong Dat, Do Tuoc, Dinh Huy Tri, L. T. Dinh and Dang Ngoc Kien, 2009. Report: Census of southern white-cheeked crested gibbons in $\mathrm{U}$ Bo and adjacent bufferzone forests, Phong Nha-Ke Bang National Park, Bo Trach District, Quang Binh province, Vietnam. Fauna \& Flora International Vietnam Programme, Ha Noi, Vietnam.

Le Trong Dat, Le Thien Duc, 2006. Report on a biodiversity survey for vertebrate fauna in Truong Son State Forest Enterprise, Quang Ninh District, Quang Binh province. Tropical Forest Trust Indochina Programme, Ha Noi, Vietnam.

Ministry of Science and Technology \& Vietnamese Academy of Science and Technology (2007): Vietnam Red Data Book, Part I. Animals. Publishing House for Science and Technology.

Mootnick A. R., 2006. Gibbon (Hylobatidae) species identification recommended for rescue or breeding centers. Primate Conservation 21: 103-138.
Mootnick, A. R., Fan Pengfei, 2011. A comparative study of crested gibbons (Nomascus). American Journal of Primatology 73: 135-154.

Nguyen Manh Ha, 2005. Report: Status of white cheek-crested gibbon (Nomascus leucogenys) in north central of Vietnam. Center for Natural Resources and Environmental Studies, Ha Noi, Vietnam.

Nguyen Xuan Dang, Nguyen Manh Ha, Bleisch V. B., 2012. Report: Biodiversity survey of Mammal, Gibbon and Loris in around the Phong Nha - Ke Bang National park, Quang Binh, Vietnam. 153 pp.

Rawson B. M, Insua-Cao P., Nguyen Manh Ha, Van Ngoc Thinh, Hoang Minh Duc, Mahood S., Geissmann T., Roos C., 2011. The Conservation Status of Gibbons in Vietnam. Fauna \& Flora International Vietnam Programme 340, Nghi Tam, Ha Noi, Vietnam.

Roos C., Boonratana R., Supriatna J., FellowesJ. R., Rylands A. B., Russell A. M., 2013. An updated taxonomy of primates in Vietnam, Laos, Cambodia and China. Vietnamese Journal of Primatology (2013) vol. 2(2): 13-26.

Ruppell 2007. Vocal Diversity and Taxonomy of Nomascus in Central Vietnam and Southern Laos. An abstract of the thesis of Julia Ruppell for the Master of Arts in Anthropology presented May 1, 2007.

Van Ngoc Thinh, Luong Viet Hung, Nguyen Tien Dung, Roos C., 2010a. Report: Population survey of white-cheeked crested gibbons in Ke Go Nature Reserve, Ha Tinh province, and Khe Net Proposed Nature Reserve, Quang Binh province. Fauna \& Flora International, Conservation International \& German Primate Centre, Ha Noi, Vietnam.

Van Ngoc Thinh, Mootnick A. R., Geissmann T., Ming Li, Ziegler T., Agil M., Moisson P., Nadler T., Walter L., Roos C., 2010b. Mitochondrial evidence for multiple radiations in the evolutionary history of small apes. BMC Evolutionary Biology 10: 74 
Van Ngoc Thinh, Mootnick A. R., Vu Ngoc Thanh, Nadler T., Roos C., 2010c. A new species of crested gibbon, from the central Annamite mountain range. Vietnamese Journal of Primatology (2010) 4: 1-12.

Van Ngoc Thinh, Nadler T., Roos C. Hammerschmidt K., 2010d. Taxonspecific vocal characteristics of crested gibbons (Nomascus spp.). Pages 121-132 in T. Nadler, B. M. Rawson, and Van Ngoc Thinh, editors. Conservation of Primates in Indochina. Frankfurt Zoological Society and Conservation International, Ha Noi, Vietnam.
Van Ngoc Thinh, Rawson B., Hallam C., Kenyon M., Nadler T., Walter L., Roos C., 2010e. Phylogeny and distribution of crested gibbons (genus Nomascus) based on mitochondrial cytochrome $b$ gene sequence data. American Journal of Primatology, 72: 1047-1054

$\mathrm{Vu}$ Tien Thinh Dong Thanh Hai, 2015. Estimation of northern yellow-cheeked gibbon (Nomascus annamensis) population size in Kon Cha Rang Nature Reserve: a new method-usinga weighted correction factor. Vietnamese Journal of Primatology (2015) vol.2 (4): 41-48. 